\title{
¿QUÉ ESTAMOS HACIENDO MAL E'N EDUCACIÓN?
}

\section{WHAT ARE WE DOING BADLY IN EDUCATION?}

\section{Agustín de la Herrán Gascón²}

\author{
Javier M. Valle López ${ }^{3}$ \\ Universidad Autónoma de Madrid
}

\section{José Luis Villena Higueras ${ }^{4}$}

Universidad de Granada

En educación, hay una serie de máximas o constantes que son aceptadas habitualmente, como sentido común. Por ejemplo que, desde la formación técnico-profesional, la investigación y las publicaciones pedagógicas se intenta

$\overline{1}$ Este texto constituye el prólogo del libro con el mismo título recientemente publicado, coordinado por nuestros colegas: Agustín de la Herrán Gascón, Javier M. Valle López y José Luis Villena

Higueras (2019) ¿Qué estamos haciendo mal en la educación? Reflexiones pedagógicas para la investigación, la enseñanza y la formación. Octaedro, S.L., Barcelona.

$2 \quad$ Profesor Universidad Autónoma de Madrid. Creador de la Perspectiva Radical e inclusiva de la formación. Miembro Comité de Calidad Redipe. Correo: agustin.delaherran@uam.es

Google Académico: https://scholar.google.es/citations?user $=$ laCCWHOAAAAJ\&hl=es

$3 \quad$ https://scholar.google.es/citations?user=3urT cUAAAAJ\&hl=es Profesor Universidad Autónoma de Madrid.

$4 \quad$ https://scholar.google.es/citations?user=j7LS6Po AAAAJ\&hl=es Profesor Universidad de Granada. mejorar la educación y, desde ella, la sociedad. También se intuye que, al menos, hay algunos aspectos en este campo que están mal y que deberían cambiar.

Cuesta algo más ver que, al pensar en lo que se precisa mejorar de la educación o lo que la rodea y en cómo solucionarlo, lo habitual es cometer un error de sesgo interpretativo al apreciarlo. Esto es, se considera que falla o que no está bien lo que no encaja con nuestras convicciones. A veces, lo que creemos no se asienta en una formación suficiente. En otras ocasiones, sí, y se puede construir antes o después de un conocimiento elaborado. 
En la medida en que el amplísimo campo de la educación es estudiado por ciencias, al menos la valoración de la comunidad científica no debería estar apenas influida por predisposiciones y creencias previas, arbitrarias o parcialmente fundadas. Podrían traer, en efecto, bien prejuicios, bien selecciones sesgadas y dualidad. Es posible que este sesgo o que este «ego en la acción», que satura a toda la sociedad, a sus sistemas y a la mayor parte de sus miembros, tenga algo que ver con los errores que se pueden cometer y observar en nuestra educación.

Casi nadie se libra del todo de su influencia: ni toda persona que lea este trabajo, ni todos los excelentes autores y autoras a quienes se ha invitado a participar y nutrir este proyecto. Como decía el catedrático de Didáctica y Organización Escolar, Félix E. González Jiménez: «La subjetividad es el fenómeno, la objetividad es una pretensión», y esa subjetividad tiene, al menos, algo de limitación y de condicionamiento.

Por eso, las contribuciones de este libro no terminan ni cierran nada. Ni pueden, ni quieren ni deben hacerlo. Más bien al contrario: abren, proponen. Al ser por definición inacabadas coadyuvan, una vez producidas, a metodologías como el diálogo transformador que enseñó Sócrates. De ahí que un destino natural de los capítulos sea el debate con base en la duda, la autoevaluación -0 mejor autocrítica- y la conciencia, para la posible evolución de la educación y del conocimiento pedagógico, tanto en el ámbito formativo como en el docente e investigador.

En el mundo de la formación, si no hay disposición sincera al cambio y ese cambio no radica en el cambio propio con base en la educación de la razón, lo que hagamos será aparente y superficial. Entendemos entonces que bajo este aprovechamiento formativo, extensible a toda la sociedad, también tenga que ver con lo que hacemos mal en la educación. En síntesis, quizá todos nosotros seamos copartícipes de lo que ocurre: lo bueno, lo mejorable y lo catastrófico.

En síntesis, este libro indaga en perspectivas, temas, problemas, proyectos, realizaciones y ausencias educativas desde un punto de vista inusual: el de la mala práctica, el de la acción errónea. No se trata de

responder, en primera instancia, a cómo hacer bien o cómo investigar mejor las cosas, sino a contribuir a completar la comprensión de la educación, desde el conocimiento de la otra orilla, de la cara alejada o de la

parte sumergida del iceberg de la educación, donde se perciben ausencias, insuficiencias, errores, ofuscaciones, fallos, incompleciones, etc.

Se trata de admitir una obviedad: que la tela de la educación tiene otro lado que apenas se mira y que, además, cuesta ver, enfocar y normalizar en el conocimiento propio y en el pedagógico. Permítasenos un ejemplo representativo: no es comparable la producción científica sobre buenas prácticas docentes, educativas e investigativas con la generada sobre malas prácticas. Sin embargo, ¿quién puede negar que existan?

Con esta perspectiva inicial, los capítulos abordan un amplio y sugerente abanico de contenidos. El objetivo de la obra es ofrecer elaboraciones centradas en lo que posiblemente, o a juicio de los autores, se hace mal en el seno de la educación. En un segundo momento, se pretende aportar perspectivas que finalmente ayuden a la transformación de la enseñanza, la educación, la formación y su investigación.

Se espera que, con ello, se puedan ofrecer visiones, análisis, propuestas, constructos y otros elementos válidos para avanzar en todos los planos y temas abordados. Podrían generarse nuevas vías formativas y otras miradas, útiles para la innovación y la investigación educativa. 
Por su orientación, las contribuciones incluyen un fuerte carácter evaluativo. Por ello, se han centrado tanto en análisis como en alternativas de cambio y la renovación pedagógica, con base más en el desempeoramiento que en la mejora. Cada protagonista lo hace eficazmente desde su propia mirada y sobre un tema que es de su especial dominio.

Así, por ejemplo, en su capítulo, «Algunas luces y muchas sombras en la implantación de educativas supranacionales. El caso de las competencias clave en España», Javier M. Valle analiza la política de la

Unión Europea sobre competencias clave como un posible ejemplo de política supranacional, no exenta de críticas, sobre todo en su forma de implantación.

Por su parte, el capítulo de Antonio Bolívar y Purificación Pérez- García, titulado «Políticas educativas sobre el profesorado: ausencias y abandonos», aborda la formación del profesorado como un problema no resuelto, desde la premisa de ser la mejor solución para la educación y una alternativa desaprovechada hasta el momento.

En la contribución titulada "Currículo escolar: aciertos y errores», escrita por José Moya y Florencio Luengo, se diserta sobre un currículo basado en competencias, desde la premisa de que esta estructuración curricular es preferible a otras formas de definición de las intenciones educativas y poniendo en evidencia que, en muchas ocasiones, este enfoque no está lo suficientemente presente en nuestras aulas.

Con el título «Educación de la sexualidad: libertad [delito y castigo] y paraíso», los profesores Fernando Barragán Medero y David Pérez Jorge se detienen en un contenido que nunca debería ser excluido del currículo, y cuya necesidad educativa actual es particularmente interesante y que habitualmente no atendido de manera adecuada.

«¿Por qué no se usan las TIC en las escuelas?» es el título que emplean Rocío Anguita Martínez, Eduardo Fernández Rodríguez y Eduardo García Zamora para ofrecernos 10 píldoras que inciden y son relevantes

para explicar de forma poliédrica y compleja por qué en las escuelas españolas estamos todavía lejos de un momento de desarrollo adecuado con el uso de las TIC.

El texto de Miguel Ángel Santos Guerra, con el sugerente título «Errores a troche y moche en la evaluación educativa», da un paso más sobre estudios anteriores relativos a errores asociados a la evaluación educativa y reflexiona sobre las principales causas que llevan a cometerlosy a mantenerse en ellos.

"¿Qué estamos haciendo mal en la universidad?», de Vicente Manzano-Arrondo, es un capítulo que critica directamente, sin adornos y sin evitarque duela, lo que a su juicio está pasando en nuestra universidad. Las razones de la diferente efectividad en entornos distintos de la enseñanza en lenguas extranjeras quedan explicadas en «Superando retos: la importancia del contexto en la educación bilingüe», que presenta Paula Ortega.

Los autores Pablo Luis Tejada Romero, Pablo Rodríguez Herrero y Pablo García Sempere describen, en «Reflexiones autocríticas de nuestra experiencia docente en el ámbito de la inclusión», los errores cometidos

por cada uno de ellos en la práctica de la educación inclusiva, con la mirada puesta en la mejora formativa desde esta perspectiva autocrítica, autoevaluativa e íntima.

"¿Qué estamos haciendo mal en la formación de Educación Social? Formación y sinergias para el avance desde el compromiso y la innovación 
desde una profesión transformadora» es el título elegido por Rubén Jiménez Jiménez para abordar la formación de educadores sociales, desde un punto de vista crítico constructivo, algo que no es muy habitual en la literatura sobre este ámbito, además de desde el campo profesional.

Porsu parte, Javier Murillo nos ofrece, bajo el título «¿Qué estamos haciendo mal en investigación educativa?», una lúcida profundización desde diversas perspectivas, sobre las explicaciones y factores por los que piensa que la investigación educativa no transforma ni mejora la educación ni la sociedad.

En el capítulo "¿Qué estamos haciendo mal? Una reflexión desde la Pedagogía», José Manuel Touriñán investiga en y desde la Pedagogía para clarificar cuestiones críticas, epistemológicas y aplicadas, relacionadas con la ciencia de la educación por antonomasia.

Y, por último, Agustín de la Herrán Gascón, se pregunta "¿Qué hacemos mal en la educación, mientras vamos en un camarote del Titanic?», ofreciendo observaciones críticas de la educación y la Pedagogía desde el «enfoque radical e inclusivo de la formación» que promueve.

Queremos cerrar esta introducción con unas palabras de Miguel Ángel Santos Guerra, cuando, al terminar su capítulo, hace una alusión directa al espíritu del libro:

Este libro puede ser una cura de humildad, tan necesaria para algunos profesionales. Una cura que nos haga poner los pies en la tierra y reflexionar con rigor y responsabilidad sobre aquello que hacemos y dejamos de hacer con el fin de mejorarlo. Bienvenido sea.

Gracias. Pudiera ser, ojalá pueda ser así, Miguel Ángel... Si así fuese, nos conformaríamos con que alcanzase a incentivar debate y reflexión entre docentes y personal de investigación... Eso ya lo podríamos considerar un éxito formativo. 